\title{
THE CATALYSIS OF CARBON DIOXIDE HYDRATION BY ACETATE ION
}

\author{
Maria J. Medeiros \\ Departamento de Quimica, Universidade do Minho, Largo do Paço, 4704-553 Braga, \\ Portugal \\ Derek Pletcher and Dmitry Sidorin \\ Department of Chemistry, The University, Southampton SO17 1BJ, \\ England
}

\begin{abstract}
Rotating disc voltammetry has been used to demonstrate that acetate ion is a catalyst for the hydration of carbon dioxide. In $0.05 \mathrm{M}$ sodium chloride solution, the addition of $50 \mathrm{mM}$ sodium acetate leads to an increase in the rate constant for the hydration of carbon dioxide from $0.9 \mathrm{~s}^{-1}$ to $8.9 \mathrm{~s}^{-1}$ at $333 \mathrm{~K}$. The rate of hydrolysis decreases with increasing ionic strength and decrease in temperature.
\end{abstract}

Keywords: hydration carbon dioxide, acetate, rotating disc electrode

Author for correspondence: Derek Pletcher

The Department of Chemistry, The University,

Southampton SO17 1BJ, England

Telephone: $44(0) 2380593519$

email: dp1@soton.ac.uk 


\section{Introduction}

The hydration of the carbon dioxide to form carbonic acid

$$
\mathrm{H}_{2} \mathrm{O}+\mathrm{CO}_{2} \longrightarrow \mathrm{H}_{2} \mathrm{CO}_{3}
$$

is known to be a slow reaction and frequently determines the rate of the chemistry of carbon dioxide in aqueous solution [1,2]. It is also known that this hydration reaction is catalysed strongly by hydroxide ion

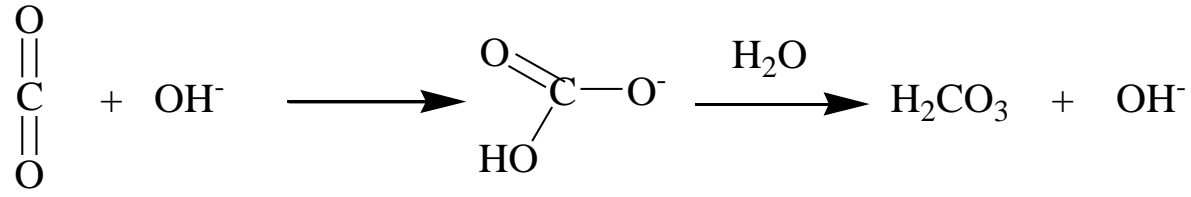

and rather more weakly by some other nucleophilic oxyanions [1,2]. We have become interested in the hydration of carbon dioxide through our work on the corrosion of carbon steel in oilfield brines and have identified enhanced unexpectedly high rates of corrosion of carbon steel in pipelines containing both acetate and carbon dioxide [3-5]. This has led us to re-examine reaction (1) and the catalysis of this reaction by acetate using voltammetry at a $\mathrm{Pt}$ rotating disc electrode. As in our corrosion studies, the experiments were carried out at a temperature of $333 \mathrm{~K}$. As far as we are aware, the catalysis of carbon dioxide hydration by acetate has not previously been reported but such catalysis by weak organic acids has potential implications for the chemistry of carbon dioxide in naturally occurring waters and in biological systems.

In aqueous solutions containing acetate and carbon dioxide, a voltammogram at a $\mathrm{Pt}$ electrode will show a reduction wave for the hydrogen evolution reaction and since the kinetics of proton reduction are rapid, the half wave potential will depend only on the $\mathrm{pH}$ of the solution. It is, however, helpful to consider the limiting current to have contributions from four reactions:

$$
\begin{aligned}
& 2 \mathrm{H}^{+}+2 \mathrm{e}^{-} \longrightarrow \mathrm{H}_{2} \\
& 2 \mathrm{HOAc}+2 \mathrm{e}^{-} \longrightarrow \mathrm{H}_{2}+2 \mathrm{OAc}^{-} \\
& 2 \mathrm{H}_{2} \mathrm{CO}_{3}+2 \mathrm{e}^{-} \longrightarrow \mathrm{H}_{2}+2 \mathrm{HCO}_{3}^{-} \\
& 2 \mathrm{CO}_{2}+2 \mathrm{H}_{2} \mathrm{O} \stackrel{\text { slow }}{\longrightarrow} 2 \mathrm{H}_{2} \mathrm{CO}_{3} \stackrel{2 \mathrm{e}^{-}}{\longrightarrow} \mathrm{H}_{2}+2 \mathrm{HCO}_{3}^{-}
\end{aligned}
$$

In all cases, the electron transfer reaction is the reduction of a proton but the current results from the transport of different species through the solution to the electrode surface. In the limiting current region, reactions (3) - (5) appear mass transport controlled since the deprotonation of the both acetic and carbonic acids are rapid reactions [6-8]. In reaction (6), it is carbon dioxide that is transported to the electrode surface and proton is formed only after 
carbonic acid is formed by hydration in a slow chemical step within a reaction layer adjacent to the electrode surface. Hence, the current for reaction (6) in kinetically limited by the hydration step.

The limiting current density measured experimentally will result from the sum of the limiting currents for the four reactions (3) - (6).

$$
j_{L, \exp }=j_{L, 3}+j_{L, 4}+j_{L, 5}+j_{L, 6}
$$

Since at a Pt electrode reactions (3), (4) and (5) are mass transport controlled in the plateau region of the reduction wave, the limiting currents for each of the reactions will be proportional to the square root of the rotation rate of the disc and the values could be estimated from the Levich equation [9]

$$
j_{L}=0.62 n F D^{2 / 3} v^{-1 / 6} c \omega^{1 / 2}
$$

where $n$ is the number of electrons transferred/electroactive molecule, $F$ is the Faraday constant, $D$ the diffusion coefficient of the electroactive species, $v$ the kinetic viscosity of the solution, $\mathrm{c}$ the concentration of the electroactive species and $\omega$ the rotation rate of the disc. In contrast, reaction (6) is an example of a ce mechanism and if the hydration reaction is slow enough, the limiting current for this reaction is independent of rotation rate and may be estimated from the equation

$$
j_{L}=F\left(k_{f} K D_{\mathrm{CO}_{2}}\right)^{1 / 2} c_{\mathrm{CO}_{2}}
$$

where $\mathrm{K}$ and $\mathrm{k}_{\mathrm{f}}$ are the equilibrium constant and forward rate constant for the hydration step of reaction (6).

In this paper we use the Pt rotating disc electrode to determine the rate constant for carbon dioxide hydration in the presence and absence of acetate.

\section{Experimental}

All solutions were prepared with deionised water from a Whatman Analyst System and sodium chloride (Fisher Scientific), anhydrous sodium acetate (Alfa Aesar, 99\%) and acetic acid (Fisher Scientific, > $99 \%$ ). Prior to experiments, the solutions were either deoxygenated with a fast stream of $\mathrm{N}_{2}(99.9 \%)$ or saturated with carbon dioxide $(99.8 \%)$; for experiments with $\mathrm{CO}_{2}$ saturated solutions, it was essential to work with a $\mathrm{CO}_{2}$ atmosphere above the solution. pH was measured with a Hanna Instruments HI 9321 Microprocessor pH Meter.

The voltammetry experiments were performed in a two compartment, glass cell with a volume, $\sim 100 \mathrm{~cm}^{3}$, and fabricated with a water jacket. The working and Pt gauze counter 
electrode were in the same compartment and the saturated calomel reference electrode was mounted within a Luggin capillary. The tip of the Luggin capillary was placed $\sim 1 \mathrm{~mm}$ from the surface of the disc working electrode. The cell was designed with a fine glass frit to allow efficient entry of gases to the solutions and a tube that allowed passage of gas over the solution throughout experiments. The temperature was controlled by circulating water from a Julabo F12 thermostat bath through the water jacket.

The voltammetry was carried out with a Princeton Applied Research Potentiostat/Galvanostat Model 263A controlled by a PC through the commercial software. Rotation rates of the RDE were controlled with a Pine Instruments Rotator Model AFCPRB and the Pt RDE (type AFE3T050PT) was also supplied by Pine Instruments. The surface of the disc was first prepared by polishing with alumina powder (Buehler) on a polishing cloth (Buehler). The potential of the Pt disc was then cycled at $100 \mathrm{mV} \mathrm{s}^{-1}$ between hydrogen and oxygen evolution in $1 \mathrm{M} \mathrm{H}_{2} \mathrm{SO}_{4}$ until the cyclic voltammogram showed the features for hydrogen adsorption/desorption and oxide formation/reduction as sharp peaks.

\section{Results and Discussion}

Figure 1 shows sets of voltammograms at a Pt rotating disc electrode in three solutions (A) $0.5 \mathrm{M} \mathrm{NaCl}$ saturated with $\mathrm{CO}_{2}$ (B) $0.5 \mathrm{M} \mathrm{NaCl}+5 \mathrm{mM} \mathrm{NaOAc}+1.4 \mathrm{mM} \mathrm{HOAc}$ (C) $0.5 \mathrm{M} \mathrm{NaCl}+5 \mathrm{mM} \mathrm{NaOAc}+$ saturated with $\mathrm{CO}_{2}$. The voltammograms were recorded at a temperature of $333 \mathrm{~K}$ and the compositions of the solutions (B) and (C) are chosen so that the bulk concentrations of acetic acid are the same [3]. It can be seen that all three solutions give single, steep reduction waves with well defined plateaux. The half wave potentials fall in the potential range -480 to $-600 \mathrm{mV}$ vs SCE. The wave for solution (A) occurs positive to those for solutions (B) and (C) because it has a lower $\mathrm{pH}$ (4.0) compared to the solutions containing acetate (5.2). The limiting currents are plotted as a function of the square root of the rotation rate in figure 2 and it can be seen that the data for all three solutions gives linear plots. Only that for solution (B) passes through the origin; the only electroactive species in this solution are proton and acetic acid and their reduction is mass transport controlled. With solution (A), reactions (3), (5) and (6) occur while with solution (C) all the reactions (3) - (6) take place. Hence, the current for the hydrogen evolution reaction in both solutions includes a component involving the hydration of carbon dioxide. This leads to the intercept at $\omega=0$. It is also clear that the intercept is larger for the solution containing acetate - acetate is catalysing the hydration of carbon dioxide. Table 1 presents a quantitative comparison of experimental and calculated values for both the half wave potentials and the slopes of the $\mathrm{j}_{\mathrm{LVS}}$ 
$\omega^{1 / 2}$ plots. The half wave potentials are estimated using the Nernst equation while the limiting current densities are calculated using equation (8) with equilibrium concentrations calculated using a software package PHREEQC 2.2 available on the web [10] modified to include the data related to acetate/acetic acid and diffusion coefficients justified previously [3-5]. It can be seen that the overall fit of the experimental data to the calculations is excellent. These calculations assume that the current for reaction (6) are independent of rotation rate, ie. the hydration reaction is slow. This is reasonable since the intercepts are $<1 \mathrm{~mA} \mathrm{~cm}{ }^{2}$ while the mass transport controlled current for the reduction of carbon dioxide in a $\mathrm{CO}_{2}$ saturated solution at a temperature of $333 \mathrm{~K}$ is the range 10 to $40 \mathrm{~mA} \mathrm{~cm}{ }^{-2}$ depending on rotation rate $\left(D_{\mathrm{CO}_{2}}=4 \times 10^{-5} \mathrm{~cm}^{2} \mathrm{~s}^{-1}, c_{\mathrm{CO}_{2}}=12 \mathrm{mM}\right)$.

The intercepts for the plots in figure 2 and the equation (9) were used to calculate the rate constants for the hydration of carbon dioxide in $0.5 \mathrm{M} \mathrm{NaCl}$ at $333 \mathrm{~K}$. The value of the equilibrium constant for the hydration was taken as $2.55 \times 10^{-3}$ [1]. The presence of the $5 \mathrm{mM}$ acetate increases the rate constant from $0.9 \mathrm{~s}^{-1}$ to $3.7 \mathrm{~s}^{-1}$. The experiments were extended to other aqueous solutions containing various concentrations of acetate and sodium chloride at $333 \mathrm{~K}$ and one set of data were obtained at $298 \mathrm{~K}$. The rate constants calculated are reported in table 2. In the absence of acetate, the value of the rate constant at $298 \mathrm{~K}$ agrees well with the literature $[1,2,11]$ while the value at $333 \mathrm{~K}$ is consistent with analyses of the rate of corrosion of carbon steel in carbon dioxide saturated brine using a carbon steel RDE [12]. The rate of carbon dioxide hydration increases substantially with increase in temperature and measurement at $333 \mathrm{~K}$ brings the rate constant into a range where the RDE technique can be applied with confidence. The most extensive set of data were obtained with $0.05 \mathrm{M} \mathrm{NaCl}$ since the rate constant increases slightly with decreasing ionic strength (as has been reported in the literature [1]). These rate constants at $333 \mathrm{~K}$ are plotted as a function of acetate concentration in figure 3. It is very clear that the rate of hydration increases with acetate concentration confirming that the anion of the weak acid is a catalyst for the hydration reaction. However, the value of the rate constant tends to plateau as the acetate concentration increases and this implies that the formation of bicarbonate occurs via a two step mechanism 
$\|_{\mathrm{O}}^{\mathrm{O}}+\mathrm{OAc}^{-} \longrightarrow \underset{\mathrm{AcO}}{\longrightarrow}{ }_{\mathrm{C}}^{\mathrm{O}}-\mathrm{O}-$

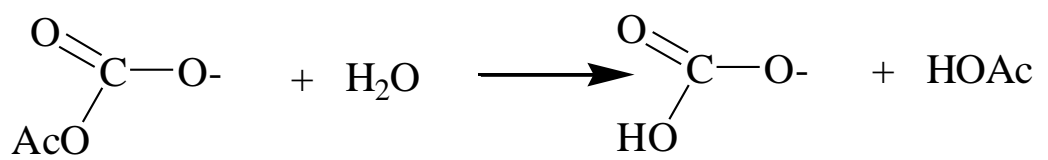

where reaction (11) can become the rate limiting step.

\section{Conclusion}

Acetate ion in solution increases significantly the rate of hydration of carbon dioxide. The extent of catalysis is more easily quantified at a temperature of $333 \mathrm{~K}$ and these are the conditions of concern in oilfield pipeline corrosion [3-5]. It is clear, however, that catalysis also occurs at lower temperatures such of those relevant to both biological and environmental studies. Moreover, semi-quantitative experiments with propionate, malonate and benzoate show that the effect is general to the anions of weak organic acids. Hence, we believe that the catalysis of carbon dioxide hydration by the anions of weak organic acids needs to be recognized and taken into account whenever such species are present in solution, either naturally occurring or added, eg. as buffers.

Acknowledgements. Most of this research was conducted while M.J.M. was a Visiting Scholar at University of Southampton. In addition, we are grateful to the Fundação para a Ciência e Tecnologia (PPCDT/QUI/55576/2004) for partial financial support of this work.

\section{References}

1. D.A. Palmer and R. van Eldik, Chem. Revs., 83 (1983) 651.

2. K. Asada in Organic and Bio-organic Chemistry of Carbon Dioxide, Eds. S. Inoue and N. Yamazaki, Halsted Press, 1982, p. 185.

3. Y. Garsany, D. Pletcher and W.M. Hedges, J. Electroanal. Chem., 538/9 (2002) 285

4. Y. Garsany, D. Pletcher, D. Sidorin and W.M. Hedges, Corrosion, 60 (2004) 1155.

5. D. Pletcher, D. Sidorin and W.M. Hedges, Corrosion, 63 (2007) 285.

6. Z. Stojek, M. Ciszkowska and J.G. Osteryoung, Anal. Chem., 66 (1994) 1507.

7. S. Daniele, I. Lavagnini, M.A. Baldo and F.Magno, Anal. Chem., 70 (1998) 285.

8. S. Daniele, M.A. Baldo and F.Simonetto, Anal. Chem. Acta, 331 (1996) 117. 
9. A.J. Bard and L.R. Faulkner, Electrochemical Methods - Fundamentals and Applications, Wiley, 2001.

10. www.brr.cr.usgs.gov/projects/GWC_coupled/phreeqc/.

11. A.L. Soli and R.H. Byrne, Marine Chem., 78 (2002) 65.

12. L.G.S. Gray, B.G. Anderson, M.J. Danysh and P.R. Tremaine, NACE Corrosion 89, Paper 464, New Orleans, 1989. 


\begin{tabular}{|c|c|c|c|c|c|c|}
\hline \multirow{2}{*}{\multicolumn{2}{|c|}{ Solution }} & \multicolumn{2}{|c|}{ - $\mathrm{E}_{1 / 2} \mathrm{vs} \mathrm{SCE} / \mathrm{V}$} & \multicolumn{2}{|c|}{$\mathrm{j}_{\mathrm{L}} / \omega^{1 / 2} / \mathbf{m A ~} \mathbf{c m}^{-2}$} & \multirow{2}{*}{ Intercept / $\mathrm{mA} \mathrm{cm}^{-2}$} \\
\hline & & expt. & calc. & expt. & calc. & \\
\hline $\mathrm{A}$ & $\begin{array}{l}0.5 \mathrm{M} \mathrm{NaCl} \\
\text { sat. with } \mathrm{CO}_{2}\end{array}$ & 0.50 & 0.48 & 0.047 & 0.047 & 0.49 \\
\hline $\mathrm{B}$ & $\begin{array}{l}0.5 \mathrm{M} \mathrm{NaCl} \\
5 \mathrm{mM} \mathrm{NaOAc} \\
1.4 \mathrm{mM} \mathrm{HOAc}\end{array}$ & 0.56 & 0.56 & 0.18 & 0.15 & 0 \\
\hline $\mathrm{C}$ & $\begin{array}{l}0.5 \mathrm{M} \mathrm{NaCl} \\
5 \mathrm{mM} \mathrm{NaOAc} \\
\text { sat. with } \mathrm{CO}_{2}\end{array}$ & 0.56 & 0.56 & 0.16 & 0.16 & 0.82 \\
\hline
\end{tabular}

Table 1 Comparison of experimental and calculated half wave potentials and limiting current densities for the three solutions $A, B$ and $C . E_{1 / 2}$ are calculated from the Nernst equation. The limiting currents at a temperature of $333 \mathrm{~K}$ are calculated using concentrations estimated by PHREEQC 2.2 and equation (8) using $D_{H^{+}}=13.6 \times 10^{-5} \mathrm{~cm}^{2} \mathrm{~s}^{-1}, \quad D_{\mathrm{HOAC}}=D_{\mathrm{H}_{2} \mathrm{CO}_{3}}=2.3 \times 10^{-5} \mathrm{~cm}^{2} \mathrm{~s}^{-1}$. 


\begin{tabular}{|c|c|c|c|}
\hline Temperature/K & $\boldsymbol{c}_{\mathrm{NaCl} /} \mathbf{m} \boldsymbol{M}$ & $\boldsymbol{c}_{\mathrm{NaOAc}} / \mathbf{m M}$ & $\boldsymbol{k}_{f} / \mathbf{s}^{\mathbf{1}}$ \\
\hline 298 & 500 & 0 & 0.04 \\
\hline 298 & 0 & 20 & 0.16 \\
\hline 333 & 50 & 0 & 0.9 \\
\hline 333 & 50 & 2 & 3.6 \\
\hline 333 & 50 & 5 & 5.0 \\
\hline 333 & 50 & 20 & 7.1 \\
\hline 333 & 50 & 50 & 8.9 \\
\hline 333 & 500 & 0 & 0.9 \\
\hline 333 & 500 & 5 & 3.7 \\
\hline 333 & 500 & 20 & 10.8 \\
\hline 333 & 0 & 20 & 6.4 \\
\hline
\end{tabular}

Table 2 Rate constants for the hydration of $\mathrm{CO}_{2}$ as a function of acetate concentration, brine concentration and temperature. 


\section{Legends to Figures}

\section{Figure 1}

Voltammograms at a Pt rotating disc electrode in three solutions (A) $0.5 \mathrm{M} \mathrm{NaCl}$ saturated with $\mathrm{CO}_{2}$ (B) $0.5 \mathrm{M} \mathrm{NaCl}+5 \mathrm{mM} \mathrm{NaOAc}+1.4 \mathrm{mM} \mathrm{HOAc}$ (C) $0.5 \mathrm{M} \mathrm{NaCl}+5 \mathrm{mM} \mathrm{NaOAc}$ + saturated with $\mathrm{CO}_{2}$. Temperature $333 \mathrm{~K}$. Rotation rates are 400, 900, 1600 and $2500 \mathrm{rpm}$.

\section{Figure 2}

Plots of limiting current density vs the square root of rotation rate for solutions (A), (B) and (C) as in figure 1 .

\section{Figure 3}

Plot of rate constant for the hydration of carbon dioxide versus the concentration of acetate ion. $0.05 \mathrm{M} \mathrm{NaCl}$. Temperature $333 \mathrm{~K}$. 